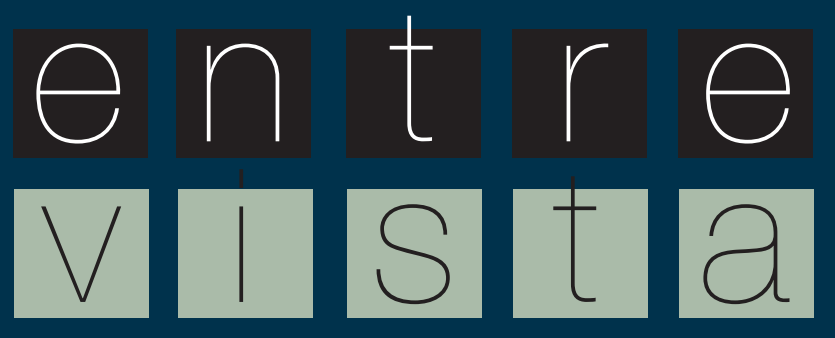


AÇÃO MIDIÁTICA, n.13. Jan./Jun. 2017. Curitiba. PPGCOM-UFPR. ISSN 2238-0701

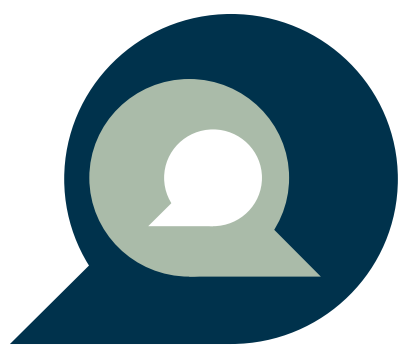


Séries. Pesquisa. Streaming. TV.

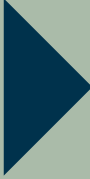




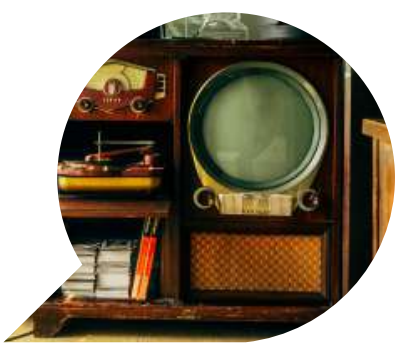

\title{
Um espectador-pesquisador: Alberto Nahum García Martínez e o estudo acadêmico sobre séries televisivas na Espanha
}

A viewer-researcher: Alberto Nahum García Martínez and the academic study about TV series in Spain

\author{
Un espectador-investigador: \\ Alberto Nahum García Martínez y el estudio académico \\ sobre las series televisivas en España
}

\section{ANDERSON LOPES DA SILVA $^{1}$}

\begin{abstract}
Resumo: Esta entrevista traz o pesquisador Alberto Nahum García Martinez (Universidade de Navarra, Espanha) discutindo a importância da pesquisa acerca de séries televisivas no cenário académico espanhol e, de forma específica, discute dois dos temas que têm atraído sua atenção nas obras mais recentes do mercado audiovisual: a questão da emoção nas séries e a figura peculiar dos "mortos-vivos/zumbis sentimentalizados” como um fenómeno das produções
\end{abstract}

\footnotetext{
1 Doutorando em Ciências da Comunicação pela Escola de Comunicações e Artes da Universidade de São Paulo (PPGCOM / ECA USP) e Mestre em Comunicação pela Universidade Federal do Paraná (PPGCOM / UFPR). Especialista em Comunicação, Cultura e Arte (PUCPR) e Bacharel em Comunicação Social - Jornalismo (FACNOPAR). Membro do GELiDis (Grupo de Estudos Linguagens e Discursos nos Meios de Comunicação), sediado na ECA USP/CNPq, e do NEFICS (Núcleo de Estudos em Ficção Seriada), sediado na UFPR/CNPq. É bolsista Capes. E-mail: anderlopps@usp.br.
} 
televisivas. Por fim, como pano de fundo das discussões sobre as séries de TV, são trazidos ao debate assuntos como a glocalização e as novas lógicas de produção, distribuição, exibição e consumo de audiovisual em plataformas de streaming.

Palavras-chave: Séries; Pesquisa acadêmica; TV; Streaming, Zumbis sentimentalizados.

\begin{abstract}
In this interview the researcher Alberto Nahum García Martinez (University of Navarra, Spain) discuss the importance of research on television series in the Spanish academic outlook and, in a specifically way, discusses two of the themes that has attracted him attention in the most recent works on audiovisual market: the issue of emotion in the TV shows and the peculiar figure of the "sentimentalized undead/zombie" as a phenomenon of the television productions. Finally, as a background to the discussions on the television series, the spanish researcher debating issues such as glocalization and new logics of production, distribution, display and consumption of audiovisual in streaming platforms.
\end{abstract}

Keywords: TV series; Academic research; TV; Streaming; Sentimentalized zombies.

Resumen: En esta entrevista el investigador Alberto Nahum García Martínez (Universidad de Navarra, España) discute la importancia de la investigación sobre series televisivas en el escenario académico español y, de forma específica, debate dos de los temas que le han atraído su atención en las obras más recientes en el mercado audiovisual: la cuestión de la emoción en las series y la figura peculiar de los "muertos vivientes/zombis sentimentalizados" como un fenómeno de las producciones televisivas. Por último, como apuntamientos secundários acerca de las discusiones sobre las series de televisión, se traen al debate asuntos como la glocalización y las nuevas lógicas de producción, distribución, exhibición y consumo de audiovisual en plataformas de streaming.

Palabras-clave: Series; Investigación académica; TV; Streaming; Zombis sentimentalizados. 


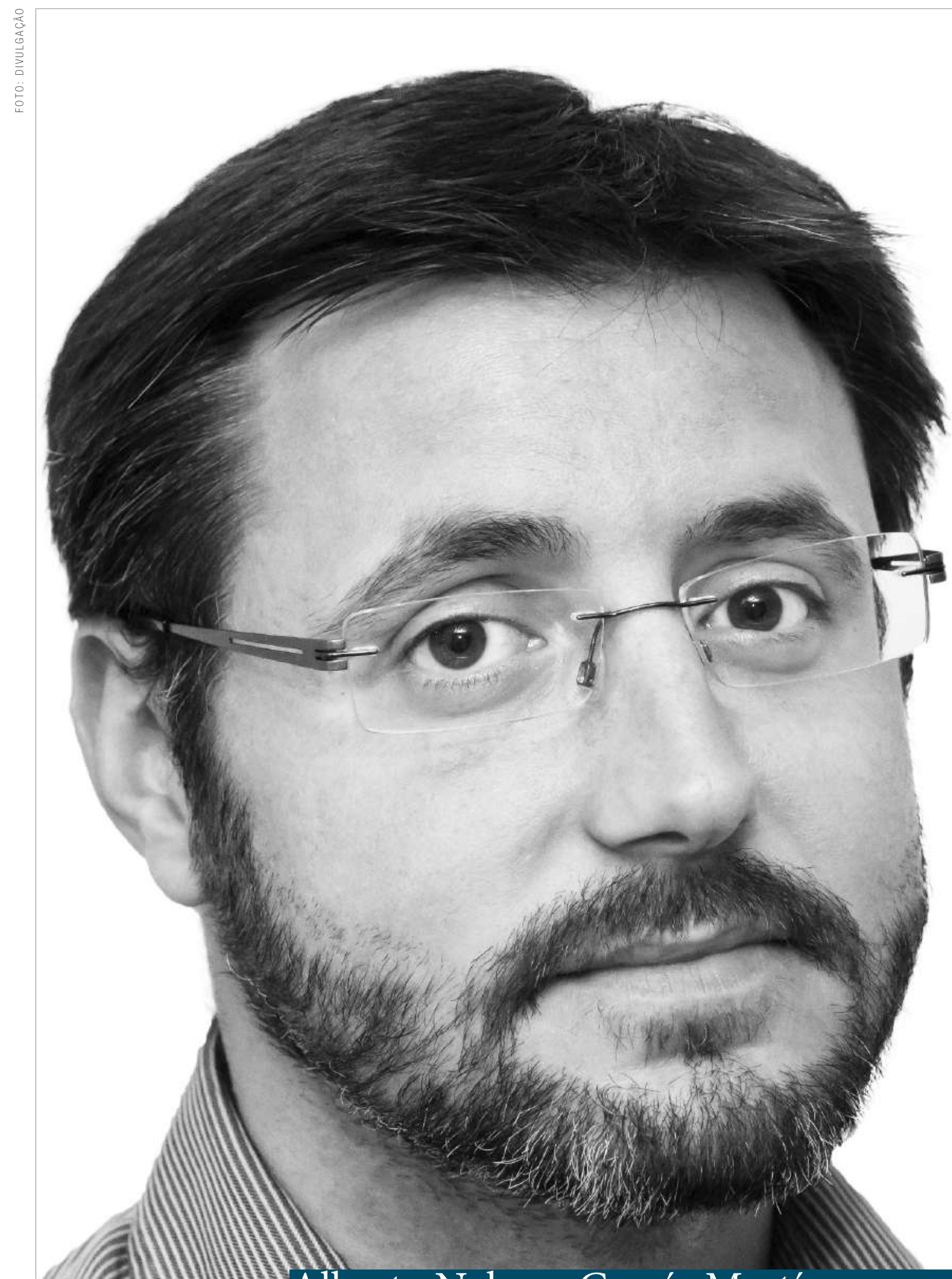




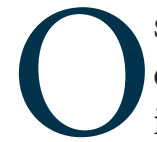

s estudos das séries e de ficção audiovisual são enquadrados, em uma tradição mais anglo-saxônica do que propriamente ibero ou latino-americana, nos chamados "Televisions Studies" ou ainda "Film and TV Studies". A importância de se observar as obras ficcionais, que transitam da TV mais tradicional às plataformas de streaming e transmidialidade, tem se mostrado nas últimas décadas cada vez mais forte com a criação de revistas especializadas no assunto e em grupos e redes de pesquisas nacionais e internacionais que mapeiam, coletam informações de audiência, analisam conteúdos e inter-relacionam dados dos mercados produtores de ficção audiovisual em grandes continentes.

Alguns exemplos mais próximos disso podem ser vistos desde o pioneiro CETVN (Centro de Estudos de Telenovela), sediado na Escola de Comunicações e Artes da Universidade de São Paulo (ECA USP) desde 1992; o A-TEVÊ (Laboratório de Análise de Teleficção), criado há pouco mais de uma década na Universidade Federal da Bahia (UFBA); até ao ainda recente NEFICS (Núcleo de Estudos em Ficção Seriada), sediado no Programa de Pós-Graduação em Comunicação da Universidade Federal do Paraná (PPGCOM UFPR), desde 2013. Para além de muitos outros importantes grupos espalhados pelo nosso país, há ainda exemplos de grandes redes integradas de pesquisadores como o projeto EuroFiction, que exerceu atividades de investigação sobre as produções ficcionais de TV no continente europeu de 1996 até aproximadamente meados dos anos 2000, e o importante Obitel (Observatório Ibero-Americano da Ficção Televisiva), em atividade ininterrupta sobre o tema desde que foi criado em 2005, atuando na América Latina (incluindo a parte hispanohablante dos EUA), Portugal e Espanha.

E é justamente na Espanha, aliás, que reside Alberto Nahum García Martínez, nosso entrevistado. $\mathrm{O}$ pesquisador, graduado em Jornalismo pela Universidade de Navarra, em 2000, concorda em gênero, número e grau com a perspectiva do aumento dos estudos voltados à serialidade ficcional. E vê, para além da relevância observada pouco a pouco, também o devido reconhecimento que vai sendo dados às investigações sobre o tema da cultura televisiva e seus reflexos nas sociedades produtoras, exportadoras, importadoras e consumidoras destes conteúdos audiovisuais.

Professor Associado da Faculdad de Comunicación, na Universidad de Navarra (Campus Pamplona), Alberto García Martínez leciona 
a disciplina de Comunicação Audiovisual desde de seu Doutorado em Communications Studies, realizado também na Universidad de Navarra. A tese intitulada "Realidad y representación en el cine de Basilio Martín Patino: montaje, falsificación, metaficción y ensayo", lhe rendeu o Premio Extraordinario de Doctorado, oferecido pela mesma instituição em que se doutorou em 2005.

Desde então, ele tem sido Pesquisador Visitante em instituições estrangeiras como Fordham University (Nova York, EUA), em 2007, e George Washington University (Washington D.C., EUA), em 2010, além de Professor Visitante na University of Stirling (Escócia, Reino Unido), em 2009, e na Universidad de Los Andes (Chile), em 2011-2012, bem como palestrante convidado da Arizona State University (EUA), em 2011.

Nos dias atuais suas pesquisas se dividem em duas grandes linhas: entre o universo dos informativos televisivos e entre a teoria e a análise da fição audiovisual. Na primeira linha estão centrados os estudos sobre formatos relativos à informação televisiva e também pesquisas sobre as análises dos conteúdos de telejornais e suas migrações transmidiáticas aos ambientes da comunicação online. Ainda se destacam nesta primeira linha contribuições como "Nuevos retos de la televisión ante la convergencia digital” (en el volumen La televisión en España, 2008), "La participación ciudadana en la web de noticias de la BBC" (Perspectivas), e artigos como "New Screens... New Languages? Spanish Broadcast News Content in the Web", apresentado no Congresso The Future of Journalism (2009).

Já em sua segunda linha de investigação - na qual esta entrevista se debruça - ele aborda as relações entre a realidade e a representação audiovisual, com um interesse mais especial pelas séries de TV anglo-saxônicas. Neste sentido, suas pesquisas têm gerado publicações acadêmicas relacionadas com diversos aspectos teóricos como "El espejo roto. La metaficción en las series anglosajonas" (Revista Latina de Comunicación Social), "La hibridación de lo real: simulacro y performatividad en la era de la post-telerrealidad" (Anàlisi), "La traición de las imágenes: mecanismos y estrategias retóricas de la falsificación audiovisual" (Zer), "El film de montaje. Una propuesta tipológica" (Secuencias), "La imagen que piensa. Hacia una definición del ensayo audiovisual"(Comunicación y Sociedad) e o recentíssimo "Emotions en Contemporary TV Series” (Palmgrave Macmillan), em 2016.

Outras publicações de nosso entrevistado podem ser vistas também 
em artigos que analisam a obra de Basilio Martín Patino, uma das figuras essenciais do cinema español. Entre estas publicações constam: "Una revisión fílmica de Franco y la Guerra Civil: Contrapropaganda y memoria en Caudillo" (Historia Social), "La realidad como estilo. Los límites de la representación en Andalucía, un siglo de fascinación" (Ámbitos), "Ironía, nostalgia y deconstrucción en Canciones para después de una guerra" (Trípodos) e também "Mirrors that Lie. The Reflection of Reality in Martín Patino" (Post Script).

Assíduo espectador de séries (especialmente as estadounidenses e británicas), atualmente, além de todas as publicações, García Martínez também colabora com o portal/revista de cultura contemporânea "Jot Down Magazine" [El País], ainda escreve para uma coluna sobre series na revista "Nuestro Tiempo" e publica críticas sobre a ficção televisiva no blog "Diamantes en Serie". Já nos projetos mais recentes, García Martínez organizou, em parceria o pesquisador Héctor J. Pérez (Universitat Politècnica de València), a Conferência Internacional "The Art of Television Series" . O evento, sediado entre os dias 09 a 10 de fevereiro de 2017, na Universidad de Navarra, teve como palestrantes convidados alguns professores renomados no campo do estudo das narrativas televisivas. Entre os conferencistas destacaram-se: Jason Jacobs (University of Queensland); Steven Peacock (Universit of Hertfordshire); Eduardo Carrero (Universidad Autònoma de Barcelona); e Guglielmo Pescatore (Università di Bologna).

Abaixo segue a entrevista concedida por Alberto Nahum García Martínez à revista "Ação Midiática - Estudos em Comunicação, Sociedade e Cultura”.

Ação Midiática $[\mathrm{AM}]$ : Eu gostaria de começar por perguntar algo que alguns pesquisadores brasileiros têm muita curiosidade: Como, segundo sua experiência, está o cenário espanhol acerca da investigação acadêmica sobre os estudos de séries e ficções de TV?

Alberto García Martínez [AGM]: O cenário espanhol sobre a pesquisa de séries e ficções de TV tem crescido muito na última década. Há vários grupos de investigação em atividade que se dedicam a estudar a serialidade e não cansam de defender teses doutorais sobre o assunto. E, poderíamos dizer ainda, que é um âmbito que está em alta, na "moda",

\footnotetext{
${ }^{1}$ Link para o programa com os trabalhos apresentados: http://www.diamantesenserie. com/2017/02/08/congreso-the-art-of-the-television-series/.
} 
e basta revisar as principais revistas acadêmicas do setor da Comunicação para constatar a relevância dos "Television Studies" na academia espanhola.

AM: No mesmo sentido da questão anterior: Qual é o espaço que você tem para as discussões sobre os produtos de ficção de TV e também outras plataformas durante suas aulas com os estudantes de Comunicação da Universidad de Navarra (na Espanha)?

AGM: Eu tenho um perfil híbrido, por assim dizer. Na graduação (com os estudantes de Jornalismo, Publicidade e Comunicação Audiovisual) eu não ensino nada especificamente relacionado com a ficção televisiva. Em outros termos, minhas aulas se centram mais em "Introduction to Film and TV Studies" e também "Broadcast Journalism". Só compartilho mais as questões relacionadas com às séries de televisão no Máster en Guión Audiovisual, uma pós-graduação com foco na escrita de roteiros tanto de séries de televisão como de longas-metragens. E aí sim, neste espaço, eu leciono e já lecionei diveros módulos: "El relato televisivo actual", "El relato en The Wire", "Un panorama de la ficción anglosajona", etc.

AM: Saindo do campo da docência e indo para o campo do mercado: você saberia dizer se as produções de ficção brasileira têm presença constante nas grades de programação das televisões espanholas? Eu me refiro tanto ao mais tradicional (como são as telenovelas brasileiras exportadas pela Rede Globo) como também ao mais recente e inovador (como "3\%", a primeira produção original de Netflix feita no Brasil, por exemplo).

AGM: Aqui, na Espanha, não tem chegado nenhuma [ficção brasileira de TV] com tanta frequência. Sim, já li alguma vez a respeito de algumas ficções brasileiras, assim como tenho escutado apresentações acadêmicas sobre o assunto em alguns congressos. Mas nunca

[... Há vários grupos

de investigação em

atividade que se

dedicam a estudar

a serialidade e não

cansam de defender

teses doutorais sobre

o assunto. 
pude ver nenhuma. Sei também que Netflix e HBO estão promovendo ficção própria em diversos países da América Latina, mas não pude ver nada disso ainda. Em todo o caso, exceto para um público hiperespecializado, aqui as produções brasileiras não são tão conhecidas.

AM: Já que tocamos no tema de Netflix... Temos visto uma crescente produção, exibição e distribuição de séries e outros formatos em plataformas de streaming como Netflix, a mais conhecida, mas também em outros meios como Amazon, Hulu, Yahoo! Screen e Crackle, por exemplo. Minhas perguntas são: $O$ que muda na pesquisa de séries com estas novas lógicas de produção? $O$ estudo de séries em streaming pede um novo olhar por parte dos investigadores?

AGM: Sim, sim. Isso muda a maneira de investigar em alguns segmentos dos “Television Studies". Talvez ainda não seja possível ver muitas mudanças nos estudos de conteúdo, isto é, não há diferenças narrativas e estéticas entre, por exemplo, uma série como "Orange Is The New Black" e "The Americans". Neste espaço, ainda, não há grandes novidades. Mas, sim, estes novos players do mercado, que você citou, provocam uma mudança nos estudos que têm que ver com a produção e recepção da serialidade. Aí sim as novas plataformas estão revolucionando a televisão.

AM: Deixando um pouco de lado os assuntos mais gerais sobre ficção televisiva, eu gostaria de focar em um aspecto mais particular de sua investigação que está representado no livro "Emotions in Contemporary TV Series” (2016), organizado por você. Por que a reflexão sobre as emoções e os afetos tem te interessado nos estudos atuais das séries?

AGM: Em primeiro lugar porque faço parte de um grupo de pesquisa da Universidad de Navarra: o grupo CEMID (Cultura emocional e identidad), uma das 8 linhas de investigação do Instituto Cultura y Sociedad (ICS). Trata-se de um grupo de investigação interdisciplinar no qual abordo questões relacionadas com a ficção. E, a partir deste grupo, cheguei ao tema das séries e das emoções. De fato, organizei um Simpósio em outubro de 2013 que serviu de gérmen para o livro. Para além desta questão pragmática, creio que o chamado "emotional turn" (giro afetivo) tem uma de suas manifestações mais visíveis no âmbito da cultura popular. E neste campo as séries de televisão ocupam um espaço privilegiado. Por isso, é essencial estudá-las a partir deste âmbito. 
AM: Outra de suas últimas publicações, dentro muitos estudos, também se interessam pela figura dos mortos-vivos nas séries. Não um zumbi "qualquer", mas um tipo em particular: aquele que passa pelo processo que você tem chamado de "sentimentalização". Estou falando do artigo "Prozac para zombis: La sentimentalización contemporánea del muerto viviente en la televisión” (2016). Quais são as características que diferencian este tipo peculiar de zumbi de outros como os das séries “The Walking Dead" ou "Z-Nation”, por exemplo?

AGM: Basicamente, a diferença mais notável com o zumbi tradicional, é que este zumbi (em séries como "iZombie", "In the Flesh" ou a australiana "Glitch") tem a capacidade de sentir. Digamos que se trata de uma subversão radical com a característica básica do zumbi. Se o zumbi era puro instinto, fome por comer vísceras humanas, estas séries localizam este tipo particular de zumbi em um terreno estético e moral onde eles deixam de representar o Mal. Eles se humanizam. São empáticos. São redimíveis. É, no fundo, um movimento muito similar ao vivido pela figura do vampiro faz 20-30 anos.

AM: Seguindo com os zumbis sentimentalizados, eu gostaria de apresentar-lhe nossa "versão brasileira" deste tipo de morto-vivo. $\mathrm{O}$ tema do zumbi sentimental, só para você ter uma ideia, já aparecia no Brasil desde 1994 na minissérie "Incidente em Antares" (Rede Globo) e em 2015 com a minissérie "Amorteamo" (Rede Globo). Você já tinha ouvido falar destas ficções ou dos temas que elas tratam?

AGM: E é uma pena que eu não tenha ouvido falar delas antes de escrever o artigo ("Prozac para zombis..."), posto que elas parecem referências muito interessantes. Em todo o caso, apesar de que a tendência à sentimentalização seja mais notável agora, já desde os anos 80 tem havido tentativas de "normalizar" e "suavizar" o zumbi. Suponho que a minissérie brasileira de 1994 se insira nestas tímidas tentativas. A novidade agora é ver como essa tendência de sentimentalizar o zumbi tem se popularizado, se tornado global e mainstream.

66 Basicamente, a
diferença mais
notável com o zumbi
tradicional, é que
este zumbi (em séries
como "ZZombie",
"In the Flesh" ou a
australiana "Glitch")
tem a capacidade
de sentir.


AM: Para encerrar este tema, poderíamos dizer que há então uma tendência "glocalizante" (uma hibridação entre o global e o local) que faz parte da construção da figura do zumbi sentimentalizado no mundo? Por exemplo, temos representantes deste tipo de morto-vivo em obras da França ("Les Revenants"), Inglaterra ("In the Flesh"), EUA ("Ressurection", “iZombie", “The Returned"), Brasil ("Incidente em Antares" e "Amorteamo") e Austrália (“Glitch"). E cada uma delas tem una característica que é particular de sua cultura na qual os zumbis sentimentalizados são produzidos. Logo, a pergunta que faço é: Isso é suficientemente forte para classificar a figura do "morto-vivo sentimental" como um fenômeno glocal das séries?

AGM: Sim, totalmente de acordo. No fim das contas, a glocalização não é mais que uma globalização adaptada aos públicos locais, já que essa revisão da figura do zumbi a partir de diversas geografias e tradições estéticas reforça a ideia de globalização de ideias e conteúdos que caracterizam a cultura televisiva atual.

AM: Por último: Quais os principais conselhos que você daría a um joven investigador ou investigadora que esteja interessado no estudo de séries e outras ficções no âmbito acadêmico?

AGM: Hmmm. Esta é a pergunta mais difícil. Suponho que eu sugeriria a ele ou ela que lesse muito os acadêmicos clássicos estadounidenses, os pioneiros dos “Television Studies". E, depois, eu aconselharia que o pesquisador não perca de vista a capacidade de ver as séries como objeto cultural, isto é, que saiba relacioná-las com questões políticas, ideológicas e estéticas que conformam o nosso tempo. 


\section{REFERÊNCIAS}

GARCÍA MARTÍNEZ, Alberto N. (ed.). Emotions in Contemporary TV Series. Londres: Palmgrave McMillan, 2016.

GARCÍA MARTÍNEZ, Alberto N. Prozac para zombi: la sentimentalización contemporánea del muerto viviente en la televisión. Brumal - Revista de Investigación sobre lo Fantástico, vol. 4, n. 1, 2016. 